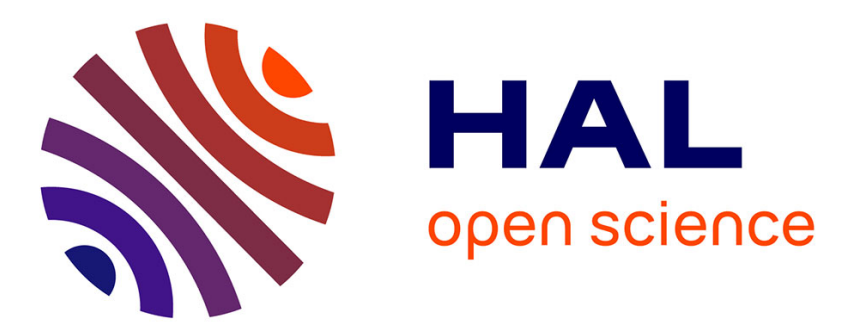

\title{
ATOMIC DATA FOR OPACITY CALCULATIONS : CARBON AND SILICON ISOELECTRONIC SEQUENCES
}

\author{
A. Pradhan
}

\section{- To cite this version:}

A. Pradhan. ATOMIC DATA FOR OPACITY CALCULATIONS : CARBON AND SILICON ISOELECTRONIC SEQUENCES. Journal de Physique IV Proceedings, 1991, 01 (C1), pp.C1-153-C1-155. 10.1051/jp4:1991118 . jpa-00249756

\section{HAL Id: jpa-00249756 https://hal.science/jpa-00249756}

Submitted on 1 Jan 1991

HAL is a multi-disciplinary open access archive for the deposit and dissemination of scientific research documents, whether they are published or not. The documents may come from teaching and research institutions in France or abroad, or from public or private research centers.
L'archive ouverte pluridisciplinaire HAL, est destinée au dépôt et à la diffusion de documents scientifiques de niveau recherche, publiés ou non, émanant des établissements d'enseignement et de recherche français ou étrangers, des laboratoires publics ou privés. 


\title{
ATOMIC DATA FOR OPACITY CALCULATIONS : CARBON AND SILICON ISOELECTRONIC SEQUENCES
}

\section{A.K. PRADHAN}

Department of Astrnomy, Ohio state University, Columbus, Ohio 43210 , U.S.A.

\begin{abstract}
The large amount of radiative data from the Opacity Project is compared with available experimental and theoretical data for the Carbon and the Silicon sequences.

Radiative data for the Opacity Project (OP; see Seaton /1/) has been calculated for all atoms and ions with $\mathrm{Z}=1-14,16,18,20$ and 26. The Carbon sequence data was computed by Luo and Pradhan /2/ and the Silicon sequence was considered by Pradhan $/ 3 /$. The calculations consist of oscillator strengths and photoionization cross sections for typically a few hundred bound states in each atom or ion. In the present report the OP data is assessed based on other calcualtions, experimental data and self consistency.
\end{abstract}

\section{A. Carbon Sequence:}

\section{A.1 Oscillator Strengths}

For the C-sequence Luo and Pradhan consider C I,N II,O III,F IV,Ne V,Na VI,Mg VII,Al VIII,Si IX,S XI,Ar XIII,Ca XV and Fe XXI. Luo et al. /3/ studied O III in particular as previous close coupling calculations had been made by Saraph and Seaton /4/ and accurate experimental lifetimes were available for comparison. The Luo et al. results are in good agreement with the earlier Saraph and Seaton work, generally wihtin 10 the states studied experimentally also agree with the OP data to within the error bars.

For C I and N II Luo and Pradhan /2/ have compared the OP values in detail with earlier theoretical calculations by McEachran and Cohen /5/ using a frozen Hartree-Fock approximation including l-dependent polarisation potentials and with the recent calculations by Victor and Escalante /6/ employing a semi-empirical model potential with adjustable parameters dependent on observed energies (or extrapolated therefrom). Luo and Pradhan find that the oscillator strengths of McEachran and Cohen and those by Victor and Escalante differ from the OP values by 30 or more for many of the transitions. The discrepancies are larger for transitions involving low lying states but are usually within 30 transitions between excited states.

The OP values for neutral Carbon agree well with the experimental measurements by Goldbach and Nollez /7/ and Goldbach et al. /8/ for the transitions considered. Although the $\mathrm{OP}$ values lie within the error bars of the experimental data, it might be pointed out that the expeimental uncertainties are usually about 15check on the OP values at the 5

A useful check on the self-consistency and accuracy of the oscillator strengths has been made by considering the level of agreement between the length and the velocity 
formulations. It is found that for most transitions the discrepancies are less than $10 \mathrm{in}$ general we expect the OP data to be accurate to 5-10that are not weak i.e. $|f| \geq 0.01$; weaker transitions would be less accurate. A more detailed assessment of the OP data for $\mathrm{C}, \mathrm{N}$ and $\mathrm{O}$ atoms and ions is currently in progress at the U.S. National Institute For Standards and Technology by Wiese and co-workers.

\section{A.2 Photoionization Cross Sections}

Photoionisation cross sections are calculated by Luo and Pradhan $/ 2 /$ for , the ions mentioned in A.1, for all bound states with $n \leq 10$ and $l \leq 3$. Autoionizing resonance structures are considered in detail. Recently a comparison has been made for C I between their OP, R-matrix results and a single configuration Hartree-Fock calculation by Nahar et al. /9/ which does not include resonances. Nahar et al. find that the $\mathrm{SCHF}$ results lie significantly lower than the OP results even for the background values ; this is probably due to neglect of configuration-interaction effects in the SCHF calculations.

\section{B. Silicon Sequence:}

Calculations for the Opacity Project have been carried out for Si I, S III, Ar V, Ca. VII and Fe XIII by Pradhan /10/ and independently by Mendoza /11/ for Fe XIII. Very little previous radiative data is available for comparison for this sequence. In Fig. $1(a, b)$ the ground state photoionization cross sections for Si I and Ca VII are shown. The Si I cross section agrees well with the earlier calculations by Mendoza and Zeippen 112/. There is a large resonance feature at the photoionization threshold of Si I ground state , $3 s^{2} 3 p^{2}\left({ }^{3} P\right)$, resulting in sizable enhancement in the near threshold cross section. This resonace is no longer present in the higher ions of the sequence as the resonance state becomes a purely bound state (e.g. Fig.1b for Ca VII). Further analysis of the $\mathrm{OP}$ data is in progress.

Acknowledgements: This work was carried out at the National Centre For Supercomputer Applications in Urbana, Illinois and at the Ohio Supercomputer Centre in Columbus, Ohio.

\section{References:}

1. Seaton,M.J., J.Phys.B:At.Mol.Phys. 20,6363(1987).

2. Luo,D. and Pradhan,A.K., J.Phys.B:At.Mol.Phys. 22,3377(1989).

3. Luo,D.,Pradhan,A.K.,Saraph,H.E.,Storey,P.J. and Yu,Y., J.Phys.B:At.Mol.Phys. 22,389(1989).

4. Saraph,H.E. and Seaton,M.J., Mon.Not.R.Astron.Soc. 193,617(1980).

5. MacEachran,P.R. and Cohen,M., J.Quant.Spectrosc.Radiat.Transf. $\mathbf{2 7}, 119(1982)$.

6. Victor,G.A. and Escalante,V., At.Data Nucl.Data Tables 40,227(1988).

7. Goldbach,C. and Nollez,G., Astron.Astrophys. 181,203(1987).

8. Goldbach,C.,Martin,M. and Nollez,G.,Astron.Astrophys., In Press.

9. Nahar,S.,Manson,S. and Pradhan,A.K. (to be submitted).

10. Pradhan,A.K. (to be submitted to J.Phys.B, 1990) .

11. Mendoza,C. (private communication).

12. Mendoza,C., and Zeippen,C., J.Phys.B.:At.Mol.Phys. 21,259(1988). 

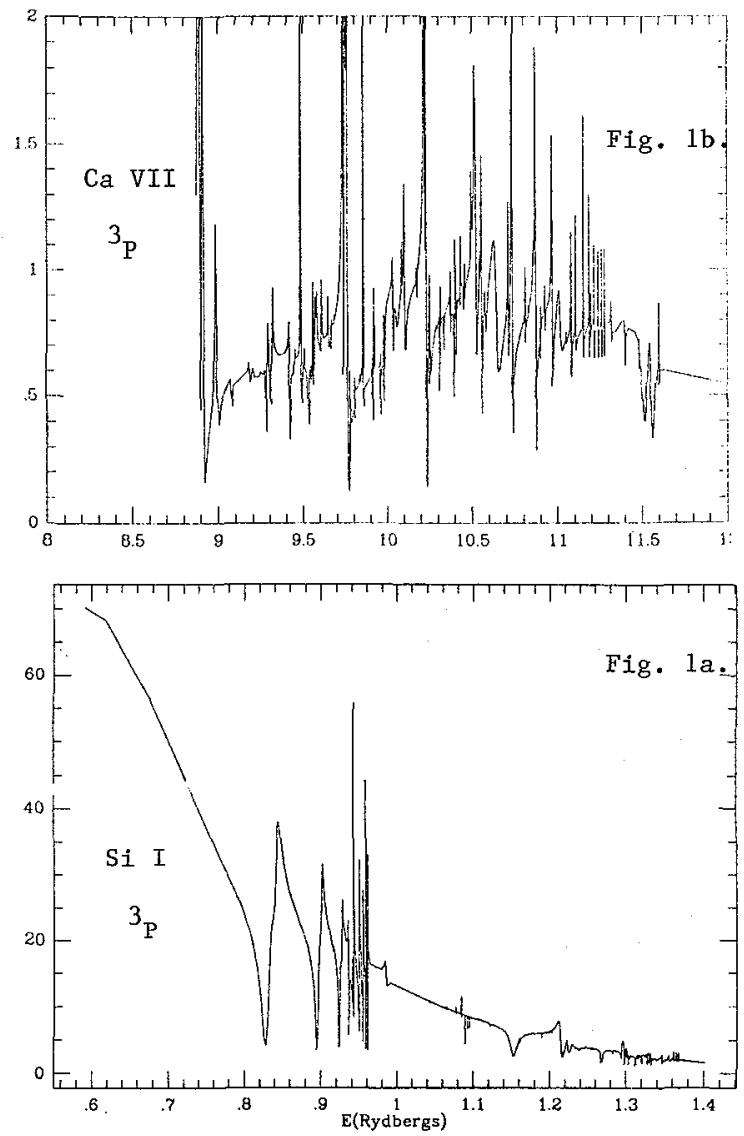